\title{
Remission of IgA Nephropathy after Allogeneic Peripheral Blood Stem Cell Transplantation Followed by Immunosup- pression for Acute Lymphocytic Leukemia
}

\author{
Yasunori Iwata ${ }^{1}$, Takashi Wada ${ }^{4}$, Akio Uchiyama ${ }^{2}$, Atsuo Miwa ${ }^{2}$, Izaya Nakaya ${ }^{1}$, \\ Tadashi Tohyama ${ }^{1}$, Yuhji Yamada ${ }^{1}$, Toshiro Kurokawa ${ }^{1}$, Takashi Yoshida ${ }^{1}$, Satoshi Ohta ${ }^{3}$, \\ Hitoshi Yokoyama ${ }^{5}$ and Hiroyuki Iida ${ }^{1}$
}

\begin{abstract}
We report a case with immunoglobulin A (IgA) nephropathy, showing IgA deposition which disappeared after peripheral blood stem cell transplantation (PBSCT) for acute lymphocytic leukemia (ALL).

In 1996, a 28-year-old man was diagnosed with IgA nephropathy by renal biopsy. Steroid therapy improved proteinuria from $3 \mathrm{~g}$ /day to $1 \mathrm{~g}$ /day. In 2003, he received PBSCT following the initial therapy for ALL. After complete remission, urinary protein and hematuria remained at between (-) and ( \pm ). In 2004, the second renal biopsy specimen revealed no deposit of $\operatorname{IgA}$ or $\mathrm{C} 3$. These findings suggested that immune reconstruction with PBSCT following immunosuppression therapy was of benefit to IgA nephropathy.
\end{abstract}

Key words: IgA nephropathy, PBSCT, ALL

(DOI: 10.2169/internalmedicine.45.1837)

\section{Introduction}

Recently, bone marrow transplantation (BMT) has been performed not only for patients with hematological malignancy but also for patients with severe autoimmune diseases such as rheumatoid arthritis (RA), systemic lupus erythematosus (SLE), systemic sclerosis and juvenile idiopathic arthritis. This therapy has been reported to improve the signs and symptoms in some cases with severe autoimmune diseases (1-3). These facts implicate that bone marrow cells, most likely including peripheral blood stem cells (PBSC), play an important role in the immune system.

BMT has shown evidence to attenuate kidney diseases including lupus nephritis (4) and immunoglobulin A (IgA) nephropathy (5) in experimental models. Moreover, PBSC differentiates to renal resident cells and contributes to the improvement of glomerular injury $(6,7)$. Therefore, these observations suggest that BMT is of therapeutic benefit to glomerulonephritis, even in humans.

Herein, we report a case of IgA nephropathy, in whom mesangial IgA deposits disappeared after treatment with allogeneic peripheral blood stem cell transplantation (PBSCT) followed by immunosuppression therapy for acute lymphocytic leukemia (ALL).

\section{Case Report}

In September 1996, a 28-year-old Japanese man was admitted to our hospital because of proteinuria and microscopic hematuria. Urinary protein excretion was 2-3 g/day. Serum creatinine was $0.6 \mathrm{mg} / \mathrm{dL}$. Serum $\mathrm{IgA}$ was $292 \mathrm{mg} /$ dL. Serum levels of complement were within the normal range. There were no other abnormal findings in his physical examination or laboratory data. Renal biopsy was performed to diagnose his renal disease. Light microscopy

\footnotetext{
${ }^{1}$ Department of Internal Medicine, Toyama Prefectural Central Hospital, Toyama, ${ }^{2}$ Department of Pathology, Toyama Prefectural Central Hospital, Toyama, ${ }^{3}$ Department of Internal Medicine, Toyama City Hospital, Toyama, ${ }^{4}$ Disease Control and Homeostasis, Kanazawa University Graduate School of Medicine, Kanazawa and ${ }^{5}$ Department of Nephrology, Kanazawa Medical University, Kanazawa

Received for publication March 24, 2006; Accepted for publication August 3, 2006

Correspondence to Dr. Yasunori Iwata, Disease Control and Homeostasis, Kanazawa University Graduate School of Medicine, 13-1 Takaramachi, Kanazawa 920-8641
} 

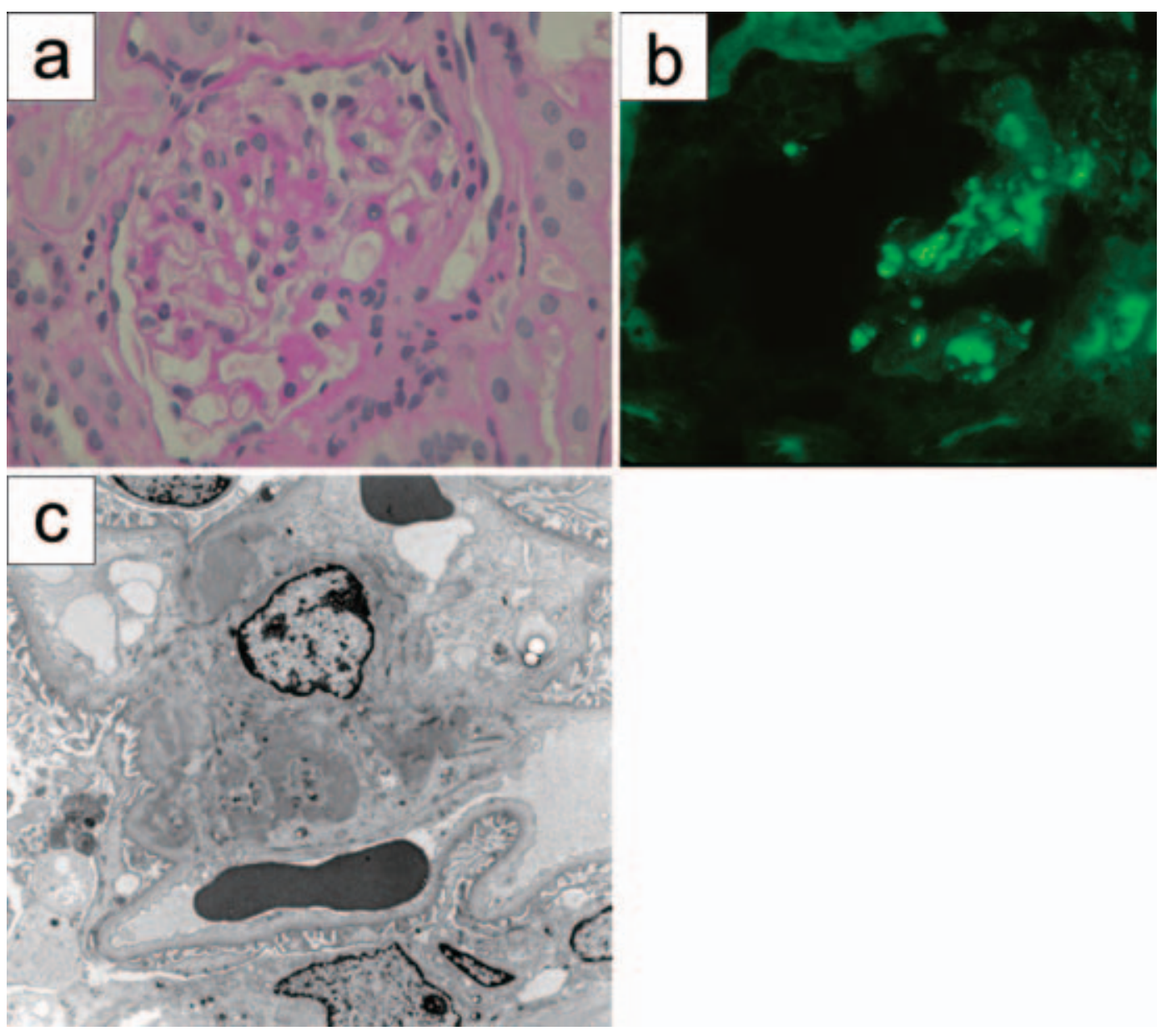

Figure 1a, b, c. Histopathology of the first renal biopsy. (a) Light microscopic findings of renal biopsy demonstrated mild mesangial proliferation and increased mesangial matrix in half of the glomeruli in the first renal biopsy (magnification $\times 400$ ). (b) Immunofluorescence microscopy showed mesangial deposits of IgA (magnification $\times 400$ ). (c) Electron microscopy demonstrated electron dense deposits in the paramesangial area (magnification $\times \mathbf{3 0 0 0}$ ).

showed total obsolescence in 7 out of 13 glomeruli. Fibrocellular crescent was detected in 3 glomeruli. In the other glomeruli, mild mesangial proliferation and increased mesangial matrix were observed. Capillary wall thickening was not clear under light microscopy (Fig. 1a). Immunofluorescence findings showed IgA deposition in mesangial areas (Fig. 1b). Electron microscopy demonstrated electron dense deposits in the paramesangial area (Fig. 1c). Then, we diagnosed this case as IgA nephropathy. Methylprednisolone (mPSL) pulse therapy was performed at a dose of 1,000 mg/ day, followed by oral prednisolone (PSL) initiated at a dose of $40 \mathrm{mg} /$ day. Four weeks after the commencement of treatment, urinary protein excretion showed a decrease to $1 \mathrm{~g} /$ day. During an outpatient evaluation, urinary protein dipstick analysis showed $(2+)$.

In January 2003, he was admitted to our hospital for continuous fever. The results of laboratory tests revealed ALL with positive $\mathrm{Ph}$ chromosome. In April 2003, after initial therapy, allogeneic PBSCT from his father was performed. Following the initial therapy, the dipstick analysis of urinary protein remained at $(2+)$, however, it went from $( \pm)$ to $(1+)$ after PBSCT. As for the initial therapy, cyclophosphamide, PSL, and other cytotoxic antitumor agents, such as vincristine, daunorubicin, etoposide, mitoxantrone, cytarabine and methotrexate were administered. In addition, as for the graft-versus-host disease (GVHD) treatment, PSL, m-PSL pulse therapy and tacrolimus were administered. After these treatments he successfully achieved complete remission. Urinary protein excretion was decreased to $0.5-0.7 \mathrm{~g} / \mathrm{day}$. Dipstick analysis of urinary protein and hematuria was maintained between (-) and ( \pm ) after these therapies. He was followed with tacrolimus, which was tapered off 8 months after PBSCT.

In August 2004, he was admitted to our hospital for evaluation of IgA nephropathy. Laboratory data were as follows: white blood cell count, $5,400 / \mu \mathrm{L}\left(5.4 \times 10^{9} / \mathrm{L}\right)$; red blood cell count, $379 \times 10^{4} / \mu \mathrm{L}\left(379 \times 10^{9} / \mathrm{L}\right)$; hemoglobin, 12.3 $\mathrm{g} / \mathrm{dL}(123 \mathrm{~g} / \mathrm{L})$; platelet count, $18.5 \times 10^{4} / \mu \mathrm{L}\left(18.5 \times 10^{9} / \mathrm{L}\right)$; total protein, $6.7 \mathrm{~g} / \mathrm{dL}(67 \mathrm{~g} / \mathrm{L})$; albumin, $3.1 \mathrm{~g} / \mathrm{dL}(31 \mathrm{~g} / \mathrm{L})$; serum urea nitrogen, $17 \mathrm{mg} / \mathrm{dL}(6.1 \mathrm{mmol} / \mathrm{L})$; creatinine, 0.9 $\mathrm{mg} / \mathrm{dL}(80 \mu \mathrm{mol} / \mathrm{L}) ; \mathrm{IgG}, 1070 \mathrm{mg} / \mathrm{dL}(10.7 \mathrm{~g} / \mathrm{L}) ; \mathrm{IgA}, 126$ $\mathrm{mg} / \mathrm{dL}$ (1.26 g/L); IgM, $48 \mathrm{mg} / \mathrm{dL}$ (0.48 g/L); C3, $92 \mathrm{mg} / \mathrm{dL}$ 

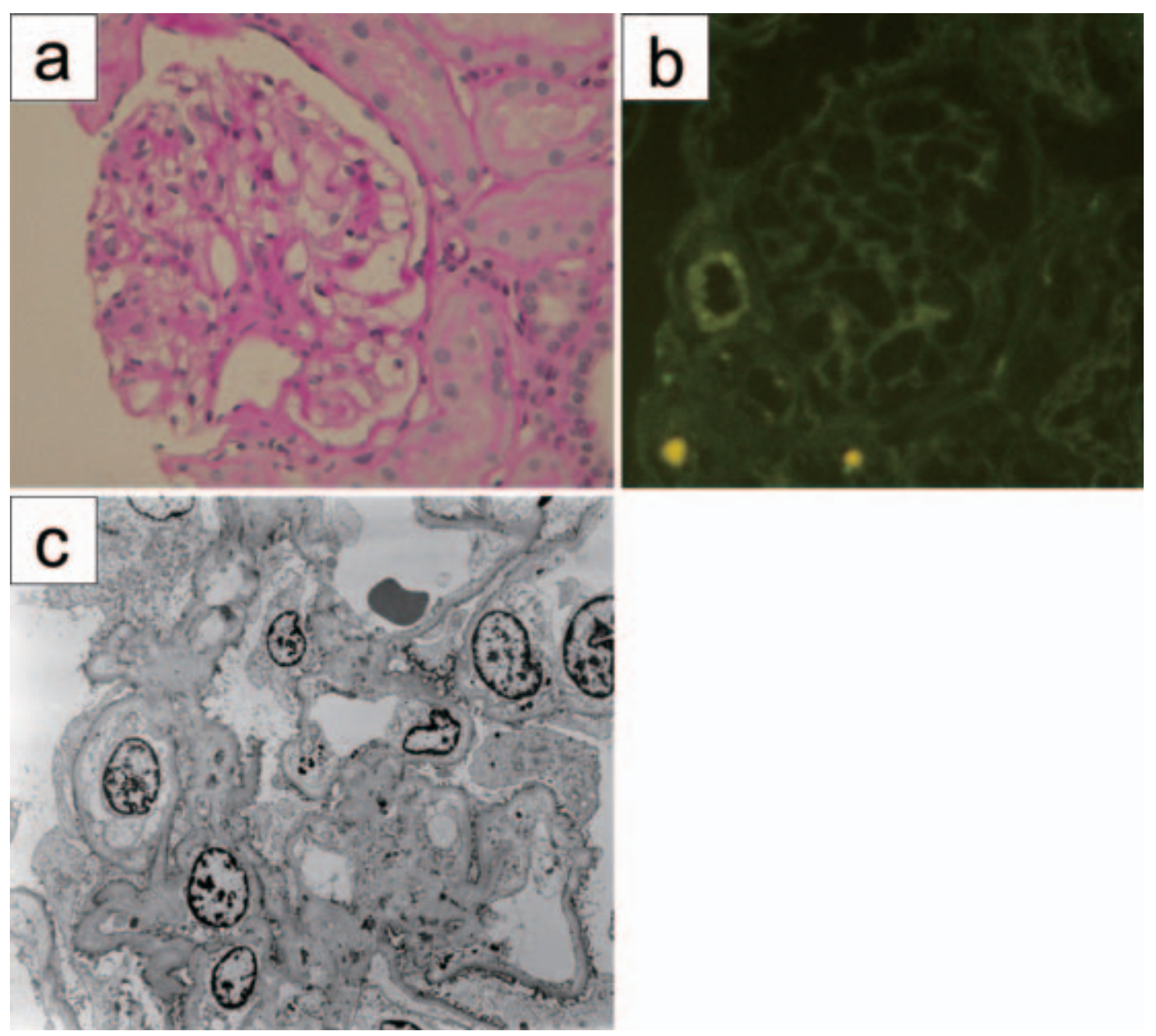

Figure 2a, b, c. Histopathology of the second renal biopsy. (a) Light microscopy showed mild mesangial proliferation and increased mesangial matrix in 3 out of 8 glomeruli (magnification $\times 400$ ). (b) No deposit of $\mathbf{I g A}$ or $\mathrm{C} 3$ was detected in immunofluorescence findings (magnification $\times 400$ ). (c) Electron microscopy demonstrated the disappearance of electron dense deposits in the paramesangial area (magnification $\times \mathbf{1 5 0 0}$ ).

(0.92 g/L); C4, $29 \mathrm{mg} / \mathrm{dL}(0.29 \mathrm{~g} / \mathrm{L}) ; \mathrm{CH} 50,46.1 \mathrm{U} / \mathrm{mL}$; Urinary analysis revealed proteinuria $( \pm)$ and occult blood (-). Urinary protein excretion was $0.5-0.7 \mathrm{~g} /$ day. Creatinine clearance was $80.1 \mathrm{~mL} / \mathrm{min}$.

Renal rebiopsy was performed 16 months after PBSCT for the therapy of ALL. Light microscopy showed total obsolescence in 5 out of 8 glomeruli. The other glomeruli showed mild mesangial proliferation and increased mesangial matrix (Fig. 2a). Crescent formation was not detected. No deposit of $\operatorname{IgA}$ and C3 was seen in immunofluorescence findings (Fig. 2b). Electron microscopy demonstrated the disappearance of electron dense deposits in paramesangial area (Fig. 2c).

In December 2004, his ALL relapsed. Initial therapy with cytotoxic antitumor agents and second PBSCT from his father was performed. However, he did not respond to these treatments and died with full leukemia. In the necropsy specimen of his kidney, deposit of IgA in mesangial area was not detected (data not shown).

\section{Discussion}

IgA nephropathy recurred in the grafts, which were transplanted in patients with endstage renal disease (ESRD) due to IgA nephropathy in some cases (8). Conversely, the deposition of $\operatorname{IgA}$ in the mesangial area disappeared in grafts, which were transplanted in patients with ESRD unrelated to IgA nephropathy (9). These results suggested that some circulating factors may play an important role for IgA nephropathy. Moreover, it has been reported that the decrease of IgA-specific suppressor $\mathrm{T}$ cell activity and the increase of IgA-specific helper $\mathrm{T}$ cell activity contribute to the pathogenesis of $\operatorname{IgA}$ nephropathy (10). Recently, novel insights have been obtained in the structural and functional abnormality of underglycosylated IgA1 molecules $(11,12)$. These findings raise the possibility that reconstruction of the immune system may have beneficial effects on the course of IgA nephropathy. In fact, reconstruction of the immune system by BMT has attenuated clinical signs and symptoms in 
some patients with severe autoimmune diseases, such as RA and SLE (1-3).

In experimental models, BMT has been reported to improve glomerulonephritis such as murine lupus nephritis (4) and $\operatorname{IgA}$ nephropathy (5). Imasawa et al reported that mesangial IgA deposition was diminished after BMT from normal mice in models of IgA nephropathy (5). They disclosed that serum levels of IgA were decreased and the molecular size of IgA became lowered after BMT, resulting in the improvement of IgA nephropathy. However, whether or not IgA deposition disappears in patients with IgA nephropathy receiving $\mathrm{PBSCT}$ or $\mathrm{BMT}$ remains to be revealed. In the present case, the serum levels of IgA decreased from 292 $\mathrm{mg} / \mathrm{dL}(2.92 \mathrm{~g} / \mathrm{L})$ to $126 \mathrm{mg} / \mathrm{dL}(1.26 \mathrm{~g} / \mathrm{L})$. Then, the mesangial deposition of IgA disappeared in the second biopsy, and urinary protein excretion improved from $1.0 \mathrm{~g} / \mathrm{day}$ to 0.5-0.7 g/day 16 months after PBSCT. In addition, there was no progression of glomerular injury after PBSCT. Thus, these findings indicate that PBSCT may have contributed to the improvement of $\operatorname{IgA}$ nephropathy in our case.

To date, PBSC has been reported to differentiate into numerous cell types such as hepatocytes (13), neurons (14), cardiomyocytes (15), skin (16), and endometrial cells (17). As for the kidney, some reports indicate that PBSC participates in the turnover of renal resident cells and contributes to renal regeneration. In the models of anti-thy1 antibodymediated glomerulonephritis, PBSC were reported to differentiate into endothelial cells and mesangial cells (7). Another study showed the differentiation of PBSC into mesangial cells from 2 weeks after BMT, even in healthy mice (18). Therefore, there was a possibility that PBSC from a healthy donor could replace injured renal resident cells and contribute to the remodeling of injured glomeruli. However, the therapeutic role of PBSC for human glomerulonephritis remains to be investigated. In the present case, we could not demonstrate the donor-derived cell in the patient's glomeruli.

The immunosuppressive agents, which were administrated for initial therapy and GVHD treatment, may have a role in the improvement of IgA nephropathy in our case. Cyclophosphamide $(19,20)$ as well as steroid therapy has been shown to be of benefit for patients with $\operatorname{IgA}$ nephropathy. Recently, cyclophosphamide has been tried in patients with progressive IgA nephropathy (21-23). Roccatello et al reported that a short course of therapy with prednisone and cyclophosphamide for 2 months, prevented proteinuria and progression to renal failure (22). Treatment with prednisolone and low-dose cyclophosphamide for the initial 3 months, following azathioprine showed an improvement in the outcome with a low risk of side effects (23). Moreover, tacrolimus, which was administered for maintenance therapy after PBSCT, has been reported to induce clinical remission in glomerulonephritis in some cases (24). However, it is unclear how often the mesangial deposits of IgA have diminished or disappeared in accordance with clinical remission. In this notion, Hotta et al reported the regression of IgA nephropathy in repeated biopsy specimens. They disclosed that the mesangial deposits of $\operatorname{IgA}$ had disappeared in 8 out of 35 patients after therapy with high doses of m-PSL and tonsillectomy (25). However, it is unknown whether this regression of IgA deposition was due to the aggressive treatment such as tonsillectomy in addition to steroid therapy or to spontaneous phenomenon. Further investigations are necessary to define the clinical and pathological modifications by immunosuppressive agents in human $\operatorname{IgA}$ nephropathy.

In conclusion, reconstruction of the immune system by bone marrow transplantation followed by immunosuppression therapy may have beneficial effects on the course of IgA nephropathy.

\section{References}

1. Tyndall A, Gratwohl A. Blood and marrow stem cell transplants in autoimmune disease. A consensus report written on behalf of the European League Against Rheumatism (EULAR) and the European Group for Blood and Marrow Transplantation (EBMT). Br J Rheumatol 36: 390-392, 1997.

2. Bekkum DW. Immune ablation and stem-cell therapy in autoimmune disease. Experimental basis for autologous stem-cell transplantation. Arthritis Res 2: 281-284, 2000.

3. Van Laar JM, Tyndall A. Intense immunosuppression and stemcell transplantation for patients with severe rheumatic autoimmune disease: a review. Cancer Control 10: 57-65, 2003.

4. Takeuchi K, Inaba M, Miyashima S, Ogawa R, Ikehara S. A new strategy for treatment of autoimmune diseases in chimeric resistant MRL/lpr mice. Blood 91: 4616-4623, 1998.

5. Imasawa T, Nagasawa R, Utsunomiya $Y$, et al. Bone marrow transplantation attenuates murine $\operatorname{IgA}$ nephropathy: role of a stem cell disorder. Kidney Int 56: 1809-1817, 1999.

6. Ito T, Suzuki A, Imai E, Okabe M, Hori M. Bone marrow is a reservoir of repopulating mesangial cells during glomerular remodeling. J Am Soc Nephrol 12: 2625-2635, 2001.
7. Rookmaaker MB, Smits AM, Tolboom H, et al. Bone-marrowderived cells contribute to glomerular endothelial repair in experimental glomerulonephritis. Am J Pathol 163: 553-562, 2003.

8. Ponticelli C, Traversi L, Feliciani A, et al. Kidney transplantation in patients with IgA mesangial glomerulonephritis. Kidney Int 60: 1948-1954, 2001.

9. Koselj M, Rott T, Kandus A, et al. Donor-transmitted IgA nephropathy: long-term follow-up of kidney donors and recipients. Transplant Proc 29: 3406-3407, 1997.

10. Sakai H. Cellular immunoregulatory aspects of IgA nephropathy. Am J Kidney Dis 12: 430-432, 1988.

11. van der Boog PJ, van Kooten C, de Fijter JW, Daha MR. Role of macromolecular IgA in IgA nephropathy. Kidney Int 67: 813-821, 2005.

12. Yasuda Y, Horie A, Odani H, et al. Application of mass spectrometry to IgA nephropathy: structural and biological analyses of underglycosylated IgA1 molecules. Contrib Nephrol 141: 170-188, 2004.

13. Alison MR, Poulsom R, Jeffery R, et al. Hepatocytes from nonhepatic adult stem cells. Nature 406: 257, 2000. 
14. Mezey E, Key S, Vogelsang G, et al. Transplanted bone marrow generates new neurons in human brains. Proc Natl Acad Sci U S A 100: 1364-1369, 2003.

15. Quaini F, Urbanek K, Beltrami AP, et al. Chimerism of the transplanted heart. N Engl J Med 346: 5-15, 2002.

16. Korbling M, Katz RL, Khanna A, et al. Hepatocytes and epithelial cells of donor origin in recipients of peripheral-blood stem cells. N Engl J Med 346: 738-746, 2002.

17. Taylor HS. Endometrial cells derived from donor stem cells in bone marrow transplant recipients. JAMA 292: 81-85, 2004.

18. Imasawa $T$, Utsunomiya $Y$, Kawamura $T$, et al. The potential of bone marrow-derived cells to differentiate to glomerular mesangial cells. J Am Soc Nephrol 12: 1401-1409, 2001.

19. Tumlin JA, Lohavichan V, Hennigar R. Crescentic, proliferative IgA nephropathy: clinical and histological response to methylprednisolone and intravenous cyclophosphamide. Nephrol Dial Transplant 18: 1321-1329, 2003.

20. Walker RG, Yu SH, Owen JE, Kincaid-Smith P. The treatment of mesangial IgA nephropathy with cyclophosphamide, dipyridamole and warfarin: a two-year prospective trial. Clin Nephrol 34: 103107, 1990.

21. Tsuruya K, Harada A, Hirakata H, et al. Combination therapy using prednisolone and cyclophosphamide slows the progression of moderately advanced IgA nephropathy. Clin Nephrol 53: 1-9, 2000.

22. Roccatello D, Ferro M, Cesano G, et al. Steroid and cyclophosphamide in IgA nephropathy. Nephrol Dial Transplant 15: 833835, 2000.

23. Ballardie FW, Roberts IS. Controlled prospective trial of prednisolone and cytotoxics in progressive IgA nephropathy. J Am Soc Nephrol 13: 142-148, 2002.

24. Loeffler K, Gowrishankar M, Yiu V. Tacrolimus therapy in pediatric patients with treatment-resistant nephritic syndrome. Pediatr Nephrol 19: 281-287, 2004.

25. Hotta O, Furuta T, Chiba S, et al. Regression of IgA nephropathy: a repeat biopsy study. Am J Kidney Dis 39: 493-502, 2002.

(C) 2006 The Japanese Society of Internal Medicine http://www.naika.or.jp/imindex.html 